\title{
Temporal profile of amygdala gamma oscillations in response to faces.
}

\section{$\operatorname{AUTHOR}(\mathrm{S}):$}

Sato, Wataru; Kochiyama, Takanori; Uono, Shota; Matsuda, Kazumi; Usui, Keiko; Inoue, Yushi; Toichi, Motomi

\section{CITATION:}

Sato, Wataru ...[et al]. Temporal profile of amygdala gamma oscillations in response to faces.. Journal of cognitive neuroscience 2012, 24(6): 1420-1433

ISSUE DATE:

2012-06

URL:

http://hdl.handle.net/2433/167501

RIGHT:

(C) 2012 Massachusetts Institute of Technology 


\title{
Temporal Profile of Amygdala Gamma Oscillations in Response to Faces
}

\author{
Wataru Sato', Takanori Kochiyama ${ }^{1}$, Shota Uono', Kazumi Matsuda ${ }^{2}$, \\ Keiko Usui ${ }^{2}$, Yushi Inoue ${ }^{2}$, and Motomi Toichi ${ }^{1}$
}

\begin{abstract}
Neuroimaging studies have reported greater activation of the human amygdala in response to faces than to nonfacial stimuli, yet little is known about the temporal profile of this activation. We investigated this issue by recording the intracranial field potentials of the amygdala in participants undergoing preneurosurgical assessment $(n=6)$. Participants observed faces, mosaics, and houses in upright and inverted orientations using a dummy target detection task. Time-frequency statistical parametric mapping
\end{abstract}

\section{INTRODUCTION}

Faces play an important role in the social activities of primates, especially humans (Burrows, 2008). In the context of evolutionary pressures, efficient detection/recognition of the faces of conspecifics would have helped humans take collective action in response to biologically important events, such as when predators were encountered. Consistent with this idea, behavioral studies have shown that the detection of faces is more rapid (Tottenham, Leon, \& Casey, 2006; Lewis \& Edmonds, 2005; Reinders, den Boer, \& Buchel, 2005; Purcell \& Stewart, 1988) and attention is more efficiently directed toward faces (Bindemann \& Burton, 2008; Bindemann, Burton, Langton, Schweinberger, \& Doherty, 2007; Theeuwes \& Van der Stigchel, 2006) compared with control stimuli involving low-level visual features or other objects.

Several neuroimaging studies have reported that, in addition to cortical visual areas such as the fusiform gyrus and superior temporal gyrus, the amygdala was more active when participants observed faces compared with control stimuli such as mosaics and houses (e.g., Ishai, Schmidt, \& Boesiger, 2005; Reinders et al., 2005; Blonder et al., 2004). Animal studies have suggested that the amygdala has a long evolutionary history associated with detecting biologically significant stimuli (LeDoux, 1996). On the basis of such data, some researchers have speculated that the amygdala may play an important role in face processing. For example, Johnson (2005) proposed that the amygdala

\footnotetext{
${ }^{1}$ Kyoto University, ${ }^{2}$ Shizuoka Institute of Epilepsy and Neurological Disorders
}

analyses revealed that the amygdala showed greater gamma-band activity in response to faces than to mosaics at 200-300 msec, with a peak at 255 msec. Gamma-band activation with a similar temporal profile was also found in response to faces versus houses. Activation patterns did not differ between upright and inverted presentations of stimuli. These results suggest that the human amygdala is involved in the early stages of face processing, including the modulation of subjective perception of faces.

may be involved in rapid face processing, which is necessary for the detection of and attentional orientation toward faces.

A more complete understanding of the role of the amygdala in face processing requires information about the temporal profile of its activity. Despite neuroimaging evidence, little progress has been made in assessing the time course of face-related amygdala activation because of the limited temporal resolution of existing neuroimaging techniques.

Kreiman, Koch, and Fried (2000) investigated human amygdala activity for face processing using intracranial single-unit recording, which can provide high temporal resolution information about neural activity; this study found that some amygdala neurons were active, with a mean latency of $240 \mathrm{msec}$, whereas participants viewed facial stimuli. Such data, along with those obtained in neuroimaging studies, suggest that amygdala activity, which appears to be more evident for faces than for control stimuli, may occur in response to faces at around 200300 msec. However, it remains unclear whether amygdala neuronal activity corresponds to hemodynamic responses, as observed in neuroimaging studies. This uncertainty stems from two sources: first, the comparison between faces and control stimuli may not have been conducted with sufficient rigor, and second, it is unclear whether the microscopic single-unit activity was reflected in the macroscopic neuronal activity (Logothetis, Pauls, Augath, Trinath, \& Oeltermann, 2001).

Although some neurophysiological studies with high temporal resolution have tested macroscopic amygdala activity in response to faces, these studies did not report 
clear results. A previous intracranial electrical recording and its ERP analysis investigated amygdala activity in response to faces and words but did not find face-specific patterns in amygdala activity (Halgren, Baudena, Heit, Clarke, \& Marinkovic, 1994). This null result may be because of the limitations of the analysis employed, as the ERP analysis detects primarily low-frequency components of electrical activity (Edwards et al., 2009). Several recent studies have suggested that the hemodynamic responses detected in neuroimaging studies may reflect electrical neural activity in high-frequency ranges, such as the gamma band (Kilner, Mattout, Henson, \& Friston, 2005; Niessing et al., 2005; Foucher, Otzenberger, \& Gounot, 2003). A previous magneto-encephalography (MEG) study also investigated amygdala activity in response to faces and other objects (Liu, Ioannides, \& Streit, 1999). The researchers estimated amygdala electrical activity on the basis of scalp MEG signals but found no face-specific amygdala activity. It should be noted, however, that the ability of scalp MEG signals to detect the activity of deep, complex brain structures, such as the amygdala, is debatable (Papadelis, Poghosyan, Fenwick, \& Ioannides, 2009; Mikuni et al., 1997). In summary, despite evidence suggestive of the existence of microscopic substrates, the temporal profile of human amygdala activity in response to faces remains uncertain, according to the results of neuroimaging studies.

To identify the temporal profile of amygdala activity in response to faces, we recorded the intracranial field potentials of the amygdala in six participants undergoing preneurosurgical assessment (Mihara \& Baba, 2001) during the presentation of faces. Two types of control condition were prepared to obtain data for comparisons with responses to faces; these involved the presentation of mosaics and houses. Mosaics were constructed from fragments of the original faces and thus contained comparable local visual characteristics. They allowed us to test whether amygdala activity for faces was attributable to basic sensory processes. Houses were prepared to test whether amygdala activity for faces reflected the sensory or cognitive processing of complex objects or was specific to faces (cf. Tanaka \& Farah, 1993). Because several behavioral studies have reported that certain types of face processing might be compromised by inversion (e.g., Yin, 1969; for a review, see Valentine, 1988), we conducted an exploratory test to assess responses to upright and inverted presentations.

Amygdala field potential data were analyzed using time-frequency analysis, which allowed detection of both high- and low-frequency electrical activities (Makeig, Debener, Onton, \& Delorme, 2004). To appropriately process the multiple-comparison problems in the timefrequency map, we conducted time-frequency statistical parametric mapping (SPM; Kilner, Kiebel, \& Friston, 2005) based on random field theory (Worsley et al., 1996). In terms of the time domain, based on previous single-unit data (Kreiman et al., 2000), we predicted that the amygdala would show greater activity in response to faces than to nonfacial stimuli at 200-300 msec following stimulus onset. With regard to the frequency domain, we predicted that significant activation would occur in the gamma band (>30 Hz; Herrmann, Frund, \& Lenz, 2010; Karakas, BaarEroglu, Ozesmi, Kafadar, \& Erzengin, 2001) because electrical activity at this frequency has been shown to relate to hemodynamic responses (e.g., Niessing et al., 2005) and because a previous study, which included time-frequency analyses of amygdala field potentials, reported that the relevant frequency for assessing amygdala activity was in the gamma band (Oya, Kawasaki, Howard, \& Adolphs, 2002). We also conducted conventional ERP analyses to compare our results with those of previous studies (e.g., Halgren et al., 1994).

In consideration of the anatomical and physiological studies of animals that have suggested that the lateral nucleus of the amygdala serves as an interface between sensory inputs and adaptive behavior (LeDoux, 2000), we focused on the lateral part of the amygdala. Additionally, we analyzed the activity in adjacent electrodes, which were located in other parts of the amygdala and the anterior temporal cortices, to test the spatial specificity of the intracranial field potentials of the amygdala. We predicted that the activation patterns of the lateral amygdala and the anterior temporal cortices would differ given that previous technical reports have identified a spatial resolution of a radius of about $1 \mathrm{~cm}$ for intracranial field potential recordings (Lachaux, Rudrauf, \& Kahane, 2003; Menon et al., 1996).

\section{METHODS \\ Participants}

Six patients (five women and one man; mean age = 34.5 years, $S D=7.9$ years) participated. All participants were native to Japan and suffered from pharmacologically intractable focal epilepsy. Intracranial electrodes were implanted in these patients during presurgical evaluations. Electrophysiological and surgical evaluations suggested that the main epileptic foci were in the hippocampus for five participants and in the lateral temporal cortex for one participant. The experiment was conducted 2.0-2.8 weeks after electrode implantation while participants were participating in a series of neuropsychological and electrophysiological assessments. Neuropsychological assessments confirmed that the language abilities and everyday memory of all participants were intact. The intelligence quotient (IQ), measured by the WAIS-R, was in the normal range for five participants; that of the sixth participant was in the mildly mentally retarded category (mean full-scale IQ $=91.8$, $S D=19.2$; mean verbal IQ $=86.7, S D$ 12.0; mean performance IQ $=100.7, S D=27.3$ ). During the experiment, no seizure activity was observed, and all participants were mentally stable. All participants were right-handed, as assessed using the Edinburgh Handedness Inventory (Oldfield, 1971), and possessed normal or corrected-tonormal visual acuity. All participants provided written 
informed consent following a full explanation of the procedure. This study was approved by the local institutional ethics committee.

\section{Anatomical Assessment}

Pre- and postimplantation anatomical assessments were conducted with structural MRI on a 1.5-T scanning system (Signa Twin Speed, General Electric Yokokawa) using T-1 weighted images. Three-dimensional fast spoiled gradientrecalled acquisition was used with the following parameters: repetition time $=12 \mathrm{msec}$, echo time $=5 \mathrm{msec}$, flip angle $=20^{\circ}$, matrix size $=256 \times 256$, field of view $=$ $22 \times 22 \mathrm{~cm}, 76$ slices, resulting in voxel dimensions of $0.8594 \times 0.8594 \times 2.0 \mathrm{~mm}$ thick. Preimplantation MRI assessments and surgical evaluations showed no structural abnormality in the bilateral amygdala of any participant.

Implantation of intracranial electrodes was performed using the stereotactic method (Mihara \& Baba, 2001). Implantation sites were chosen based solely on clinical criteria. To test the bilateral activity of the amygdala, six electrodes were implanted horizontally in each hemisphere. Postimplantation anatomical MRI assessments confirmed that the third (numbered from the medial to the lateral sides) electrode was implanted in the lateral amygdala of all participants (Figure 1). The first, second, fourth, fifth, and sixth electrodes were located in the entorhinal cortices/superficial part of the amygdala, medial amygdala, lateral border between the amygdala and the white matter, medial border between the white matter and anterior temporal cortices, and anterior temporal cortices, respectively.

\section{Stimuli}

The stimuli were created using grayscale photographs (Figure 2). The face stimuli consisted of photographs of full-face neutral expressions displayed by seven female and seven male Japanese models. The mosaic stimuli were constructed by dividing all the face stimuli into 25 vertical $\times$ 25 horizontal squares, which were reordered using a fixed randomization algorithm. As a result of this rearrangement, the stimuli were unrecognizable as faces. The house stimuli consisted of photographs of 14 houses. Inverted images of these photographs were created to serve as stimuli under the inverted condition. All stimuli subtended $7.6^{\circ}$

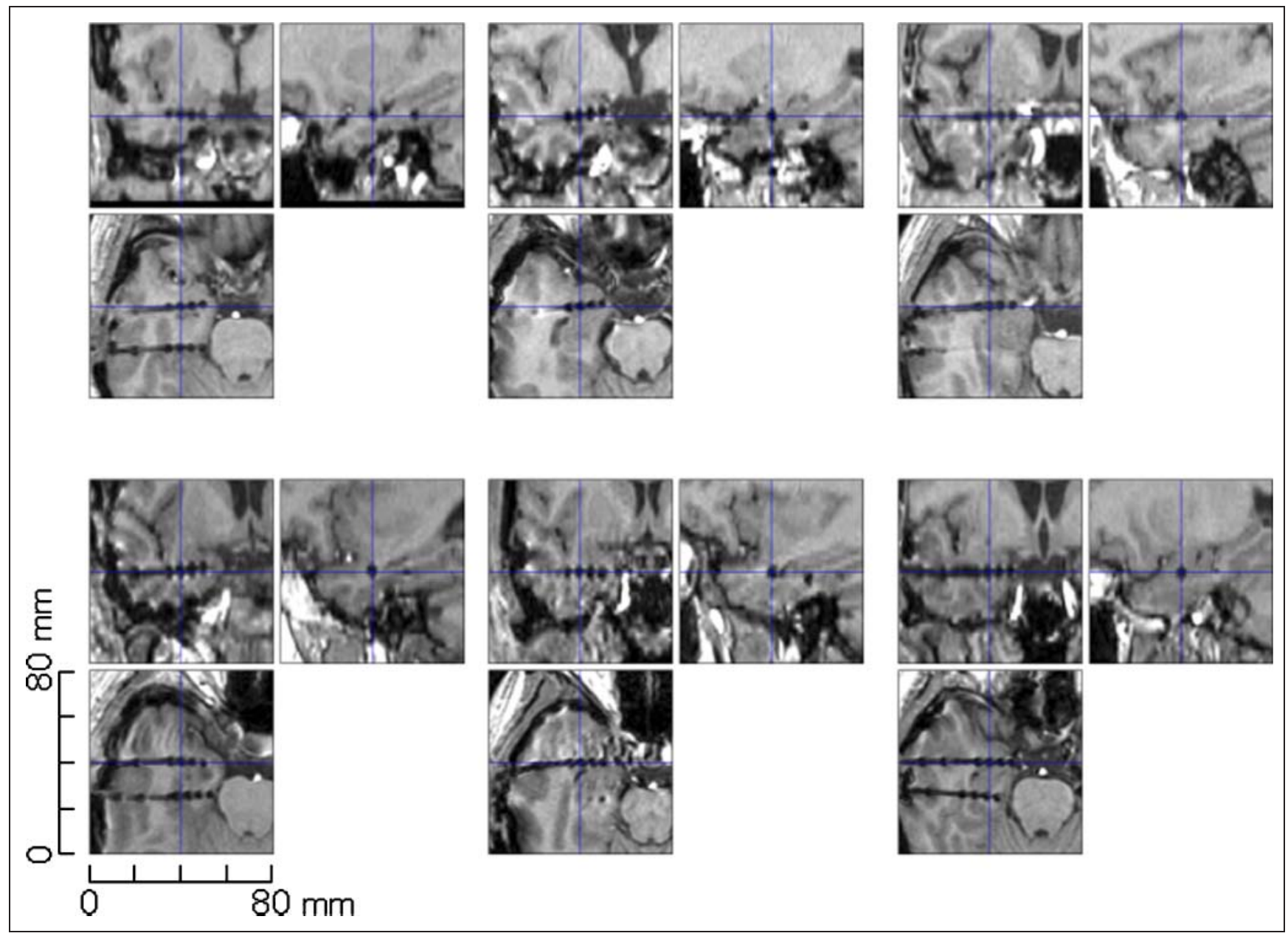

Figure 1. Anatomical magnetic resonance images for all participants. Blue crosses indicate the locations of the lateral amygdala electrodes. 


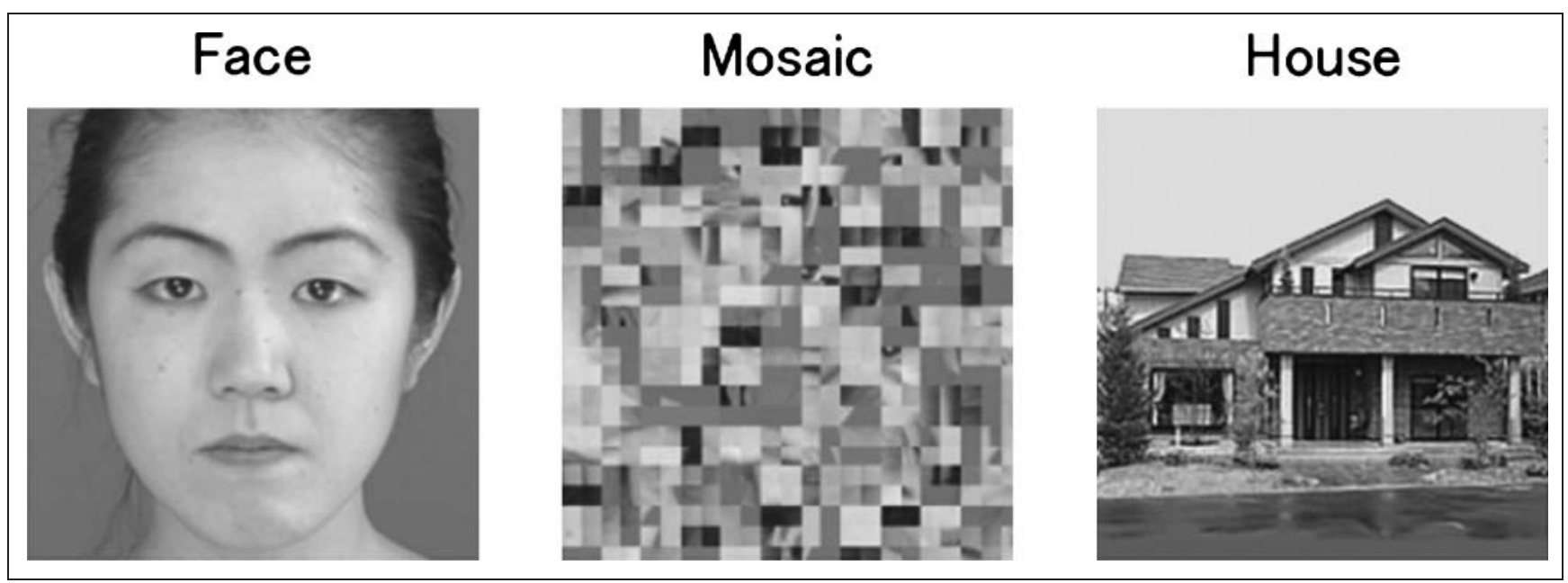

Figure 2. Examples of stimuli.

vertically $\times 7.6^{\circ}$ horizontally. The mean luminance for all images was held constant using MATLAB 6.5 (Mathworks, Natick, MA).

\section{Procedure}

The presentation of stimuli was controlled by SuperLab Pro 2.0 (Cedrus) and implemented on a Windows computer (FSA600, Teknos). The stimuli were presented on a 19-in. CRT monitor (GDM-F400, Sony) with a refresh rate of $100 \mathrm{~Hz}$ and a resolution of $1024 \times 768$ pixels. The participants' responses were recorded using a response box (RB-400, Cedrus).

Experiments were conducted individually in a quiet room. Each participant was seated comfortably $0.57 \mathrm{~m}$ from the monitor with her or his head supported by a chin-and-forehead rest.

Each stimulus was presented twice. Additionally, a red cross was presented as the target in 20 trials, yielding 188 trials (28 trials each for the upright face, upright mosaic, upright house, inverted face, inverted mosaic, and inverted house stimuli, and 20 target trials) for each participant. Stimuli were presented in a random order. In each nontarget trial, the stimulus was presented centrally for $1000 \mathrm{msec}$ after a cross had appeared at a fixation point for $500 \mathrm{msec}$. In each target trial, the red cross, instead of the photo stimulus, was presented until participants responded. Participants were asked to detect a red cross and then to press a button with the right forefinger as quickly as possible. These dummy tasks confirmed that participants were attending to the stimuli and also prevented the explicit processing of the content of stimuli. Post hoc debriefing confirmed that the participants were not aware that the purpose of the experiment involved the investigation of faces. Participants were also instructed not to blink while stimuli were being presented. The intertrial interval varied randomly between 2000 and 5000 msec. To avoid habituation and drowsiness, participants were given short rests upon completion of one quarter of the trials. Before data collection, participants were familiarized with the procedure through training by participating in a block of 10 trials.

\section{Data Recording}

Intracranial field potential recording was conducted using depth platinum electrodes $(0.8-\mathrm{mm}$ diameter; Unique Medical, Tokyo, Japan). Electrodes were referenced to the electrodes (2.3-mm diameter; Ad-tech, Racine, WI) embedded within the scalp of the midline dorsal frontal region. Impedances were balanced and maintained below $5 \mathrm{k} \Omega$. Data were amplified, filtered on-line (band pass, $0.5-120 \mathrm{~Hz}$ ), and sampled at $1000 \mathrm{~Hz}$ by an EEG system (EEG-1100, Nihon Kohden, Tokyo, Japan). Vertical and horizontal EOGs were simultaneously recorded using $\mathrm{Ag}-\mathrm{AgCl}$ electrodes (Nihon Kohden, Tokyo, Japan). As in previous studies (Lachaux et al., 2003), off-line visual inspection confirmed that no contamination of EOGs by intracranial field potentials had occurred. An unobtrusive video recording of events was made using a video camera attached to the EEG. Off-line checks of the videos confirmed that all participants were fully engaged while participating in the tasks.

\section{Data Analysis}

Intracranial recording data were resampled using Psychophysiological Analysis Software 3.3 (Computational Neuroscience Laboratory of the Salk Institute, La Jolla, CA) implemented using MATLAB 6.5 (Mathworks, Natick, MA). Data obtained during $1500 \mathrm{msec}$ were sampled for each trial; prestimulus baseline data were collected for 500 msec (while the fixation point was presented), and 
experimental data were collected for 1000 msec after stimulus onset at a sampling rate of $200 \mathrm{~Hz}$. Any epoch with a deviation in amplitude of $\geq 5 S D$ from the mean for each electrode for each participant was rejected as an artifact. The frequencies of artifact-contaminated epochs for the lateral amygdala electrodes were very low $(<1.1 \%)$.

Time-frequency SPM analyses (Kilner, Kiebel, et al., 2005) were performed using SPM5 (www.fil.ion.ucl.ac. uk/spm/) implemented using MATLAB 6.5 (Mathworks, Natick, MA). The time-frequency (power) maps were calculated first for each trial using continuous wavelet decomposition with seven-cycle Morlet wavelets from 4 to $100 \mathrm{~Hz}$, which covered theta (4-8 Hz), alpha (8-12 Hz), beta $(12-30 \mathrm{~Hz})$, and gamma $(30-100 \mathrm{~Hz}$; cf. Herrmann et al., 2010) activity. Wavelet analyses were conducted with prestimulus baseline corrections. Although debate regarding the baseline correction problem persists (e.g., Woldorff, 1993), our preliminary analyses without baseline corrections yielded identical patterns of significant effects, suggesting that the baseline correction procedures had little effect on the present data. To ensure Gaussianity, the timefrequency maps were then log-transformed and smoothed with a 2-D Gaussian kernel of full-width-at-half-maximum of $12 \mathrm{~Hz}$ in the frequency domain and $96 \mathrm{msec}$ in the time domain (cf. Kilner, Kiebel, et al., 2005).

The time-frequency maps were then entered into the general linear model (GLM) based on a fixed effects analysis of the pooled error from all trials for all participants. The GLM included stimulus type (face, mosaic, and house), presentation condition (upright and inverted), and laterality (left and right) as factors of interest and participant blocks (six participants) as a factor of no interest. Full-scale IQ was also included in the model as a covariate of no interest.

To ensure the assumption of an independent and identically distributed error for the GLM, corrections for nonsphericity were applied. We modeled the covariance components representing dependency and uneven variance between levels. Covariance components were estimated from the pooled active bins (exceeding an uncorrected $F$ threshold of $p<.001$ for any effect) with the Restricted Maximum Likelihood procedure (Friston et al., 2002). The inverse of the square root of the estimated covariance matrix was used to prewhiten the data and design matrix. The least squares estimation was performed on the whitened data and design matrix, giving the maximum likelihood parameter estimates. Finally, time-frequency $\operatorname{SPM}\{T\}$ values were calculated for each contrast.

Statistical inferences performed on time-frequency $\operatorname{SPM}\{T\}$ data were based on random field theory (Kilner, Kiebel, et al., 2005; Worsley et al., 1996). We used the restricted time-frequency window (corresponding to the small volume correction in a standard SPM) for the window of interest (WOI). On the basis of our predictions, we defined the WOI as the gamma-band range during 200-300 msec. We applied the WOI to test our predic- tions on the contrast between faces and mosaics and between faces and houses. To test whether common time-frequency regions were active for these contrasts, we conducted conjunction analyses with a conjunction null hypothesis (cf. Nichols, Brett, Andersson, Wager, $\&$ Poline, 2005). To test whether the activation patterns differed between hemispheres, we also tested the interactions of Stimulus type $\times$ Laterality using WOI. We also tested the effects and interactions related to presentation condition using WOI. Other time-frequency ranges were corrected for whole time-frequency regions $(0-1000 \mathrm{msec}$, $4-60 \mathrm{~Hz}$ ) during the poststimulus periods. Significantly activated time-frequency clusters were identified if they reached the extent threshold of $p<.05$, corrected for multiple comparisons, with the height threshold of $p<.01$ (uncorrected). The equivalent $Z$ value was used to report the inferential results. We also conducted analyses with more liberal thresholds for descriptive purposes.

To confirm the consistency of effects for all hemispheres among all participants, we also conducted conjunction analyses based on a global null hypothesis (Friston, Holmes, \& Worsley, 1999). It has been proposed that a conjunction analysis using a fixed effect model is sufficient for inferring a qualitative characteristic of a population (Friston, Holmes, Price, Buchel, \& Worsley, 1999). We used the height threshold of $p<.01$ (uncorrected) for these analyses.

For display purposes, data on the effect size of lateral amygdala activity were extracted from the timefrequency maps by sampling the rectangular window extending $6 \mathrm{~Hz}$ in the frequency dimension and $30 \mathrm{msec}$ in the time dimension at the center of the peak timefrequency point specified by the contrasts between faces and mosaics.

To test the spatial specificity of amygdala activity, data from adjacent electrodes were also analyzed using the same procedures as that used for the time-frequency analyses and the same GLMs as used for the lateral amygdala. On the basis of the results of the analyses of the lateral amygdala, only the main effects of stimulus type (face versus mosaic; face versus house) were tested using the conjunction analyses.

ERP analyses were also conducted on lateral amygdala activity using SPM5. We used a novel variant of the 3-D sensor space-time SPM approach (Litvak et al., 2011; Kilner \& Friston, 2010). This method allowed addressing the multiple-comparison problem in ERP analyses on the basis of random field theory (Worsley et al., 1996). Because we focused on a single electrode, the 3-D sensor space-time SPM was reduced to the single sensor-time SPM. Data from all trials for all participants were converted into line images after baseline correction and then entered into the GLM in the same way as the time-frequency SPM analyses. On the basis of the results of the time-frequency SPM analyses, only the main effects of stimulus type (face vs. mosaic; face vs. house) were tested. Significant activities were identified with the extent threshold of $p<.05$, 
corrected for multiple comparisons, with the height threshold of $p<.01$ (uncorrected).

\section{RESULTS}

\section{Behavioral Performance}

Performance on the dummy target detection task was perfect (correct identification rate $=100.0 \%$; mean $\mathrm{RT}=$ $403.1 \mathrm{msec}, S D=28.8 \mathrm{msec}$ ).

\section{Activity of the Lateral Amygdala}

The field potential data for the lateral amygdala (Figure 3A), which were wavelet-transformed, were entered into GLM, including the effects of Stimulus Type (face, house, and mosaic), Presentation Condition (upright and inverted), and Laterality (left and right). For the main effect of Stimulus Type, the time-frequency SPM of the comparison between faces and mosaics revealed significant gamma-band
Figure 3. Activity of the lateral amygdala. (A) Grand-averaged time-frequency maps of the amygdala for faces, mosaics, and houses with baseline corrections. The results under both presentation conditions and for both hemispheres are combined. White crosses indicate the locations of activation foci for faces versus mosaics ( $255 \mathrm{msec}, 63 \mathrm{~Hz}$ ). $\mathrm{F}=$ frequency; $\mathrm{T}=$ time. (B) Thresholded (top) and full-colored (bottom) statistical parametric maps for comparisons of faces versus mosaics and faces versus houses and for conjunction analysis. $\mathrm{F}=$ frequency; $\mathrm{T}=$ time. (C) Mean (with $S E$ ) effect size of the lateral amygdala at the peak activation focus for faces versus mosaics. The results for both hemispheres are combined.
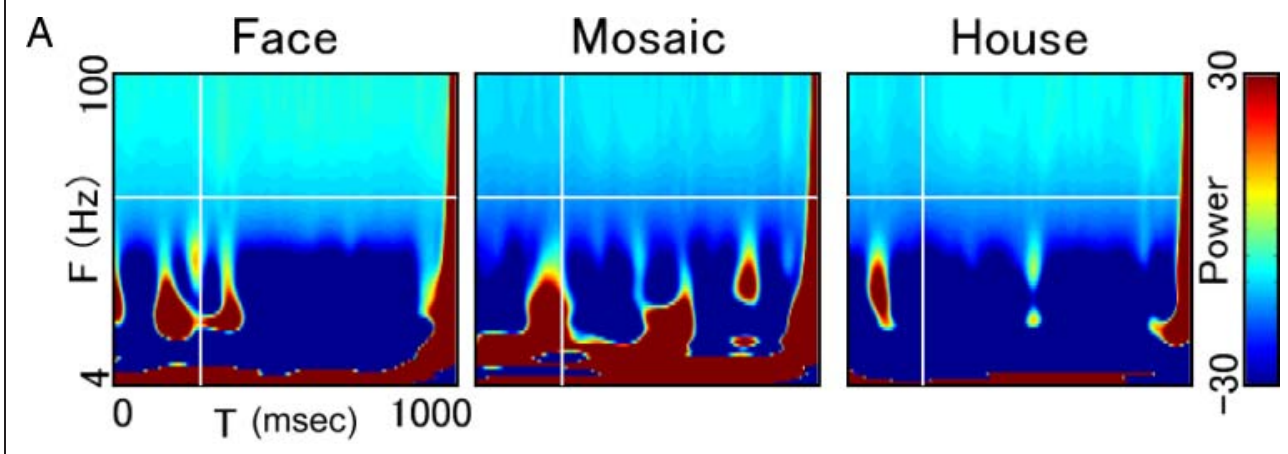

B Face vs. Mosaic Face vs. House
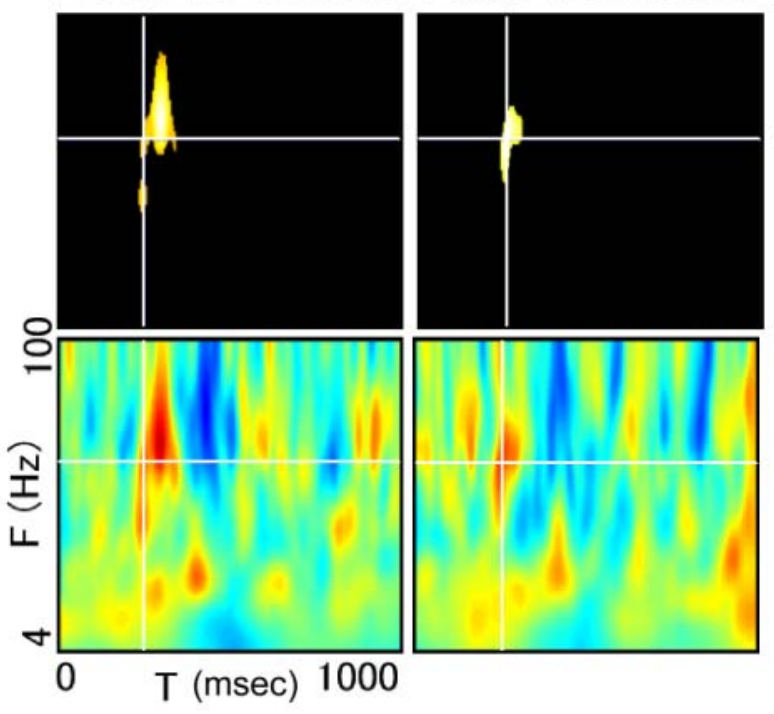

Conjunction
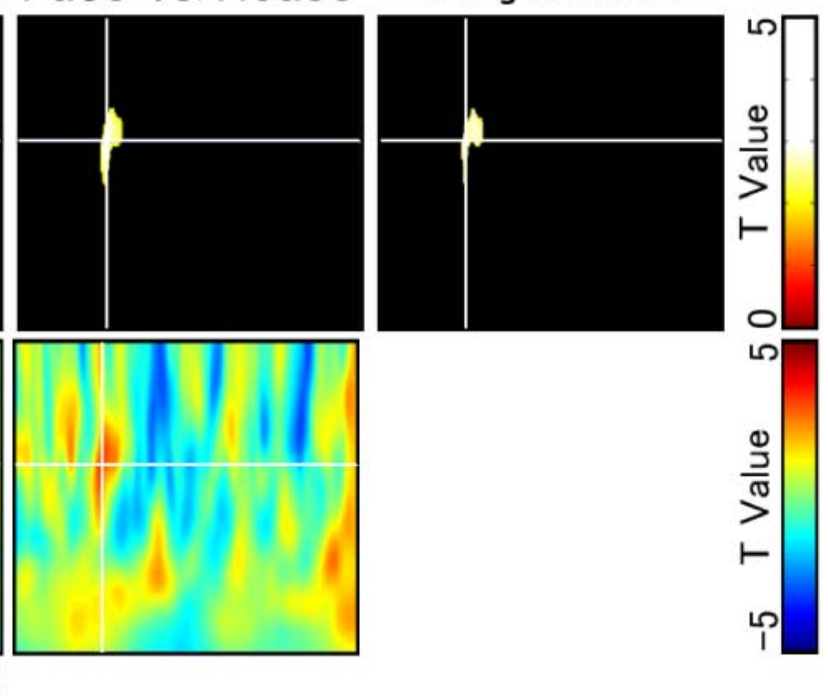

C

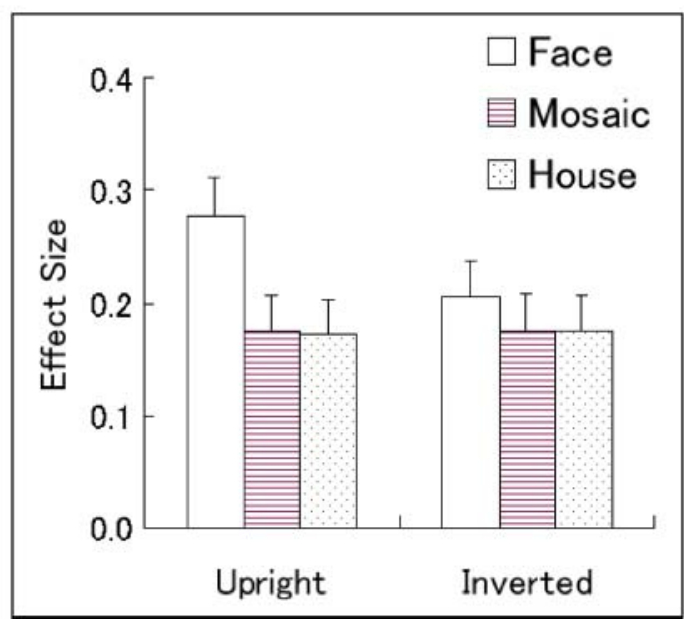


Figure 4. Grand-averaged ERP waveforms elicited by faces (red), mosaics (green), and houses (blue). Results under both presentation conditions and for both hemispheres are combined.

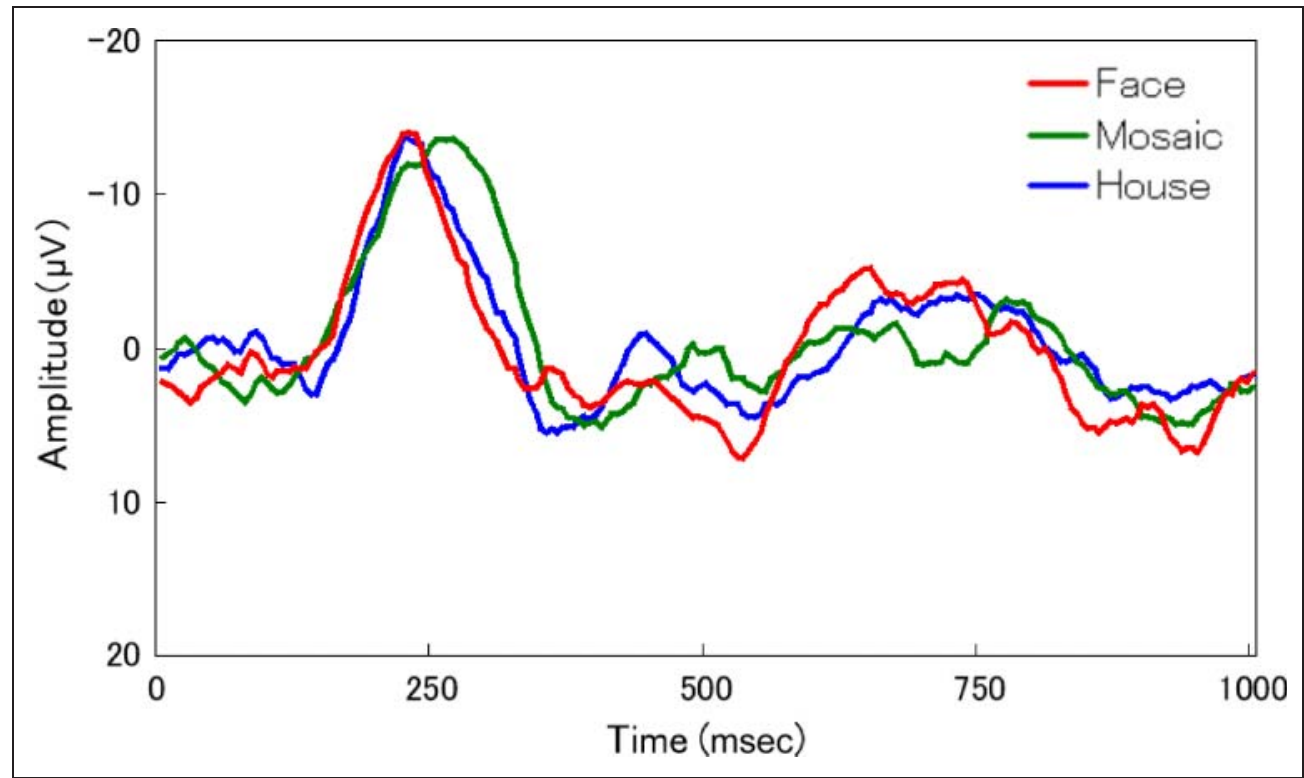

activity at 200-300 msec (peak at $255 \mathrm{msec}, 63 \mathrm{~Hz}, Z=2.99$; peak at $250 \mathrm{msec}, 45 \mathrm{~Hz}, Z=2.75$; Figure 3B and C; Figure A1 for individual data). The cluster extended outside the WOI into the later time region (peak at $305 \mathrm{msec}, 68 \mathrm{~Hz}$, $Z=4.43$ ). The comparison between faces and houses also revealed significant activation in the gamma band at 200$300 \mathrm{msec}$ (peak at $260 \mathrm{msec}, 63 \mathrm{~Hz}, Z=3.32$ ). Conjunction analyses confirmed that the common time-frequency region was significantly active for faces versus mosaics and for faces versus houses (peak at $255 \mathrm{msec}, 63 \mathrm{~Hz}, Z=$ 2.99; peak at $250 \mathrm{msec}, 52 \mathrm{~Hz}, Z=2.38$ ). Conjunction analyses across participants also confirmed activation in the cluster for faces versus mosaics and for faces versus houses $(p<.01)$, indicating that the amygdala activity was significant in each and every participant.

No significant effect of Stimulus Type was observed for any of the other time-frequency regions, and no significant interactions of Stimulus Type $\times$ Laterality were found. Main effects and interactions related to presentation condition were also not significant. To review the null effect of presentation condition, we further tested the contrasts of faces versus mosaics and faces versus houses under each upright and inverted presentation condition. We examined the activation in the cluster that was common for faces versus mosaics and for faces versus houses in the above analysis. All these contrasts showed significant activation in the cluster (peak at 250, 250, 295 , and $295 \mathrm{msec} ; 62,60,70$, and $70 \mathrm{~Hz} ; Z=3.50$, $3.67,4.48$, and 2.85 for upright faces vs. upright mosaics, upright faces vs. upright-houses, inverted faces vs. inverted mosaics, and inverted faces vs. inverted houses, respectively).

For descriptive purposes, several nonsignificant results are presented. When the analyses were conducted without extent thresholds, we found small clusters for both comparisons of faces versus mosaics and faces versus houses in the beta-gamma band at 400-500 msec (faces vs. mosaics: peak at $410 \mathrm{msec}, 27 \mathrm{~Hz}, Z=2.84$; faces versus mosaics: peak at $425 \mathrm{msec}, 29 \mathrm{~Hz}, Z=2.58$ ). We did not find more rapid activities using our predefined height threshold. When the analyses were conducted with a more liberal height threshold $(p<.05$, uncorrected) to search for more rapid components, we found activation clusters at 100-200 msec in the gamma (peak at $110 \mathrm{msec}, 54 \mathrm{~Hz}, Z=1.67$ ) and alpha-beta (peak at $185 \mathrm{msec}, 14 \mathrm{~Hz}, Z=1.88$ ) bands only for the comparison between faces and houses.

ERP analyses were conducted on lateral amygdala activity to compare our results with those of previous studies (Figure 4; Figure A1 for individual data). Visual inspection of grand-averaged ERP waveforms indicated that faces, houses, and mosaics commonly elicited a first negative component peaking at about $250 \mathrm{msec}$. The comparisons of faces versus mosaics and faces versus houses revealed no significant activity. When the analyses were conducted for descriptive purposes with a more liberal height threshold ( $p<.05$, uncorrected), the comparison of faces versus houses revealed activation during $250-300 \mathrm{msec}$ (peak at $260 \mathrm{msec}, Z=1.93$ ).

\section{Activity of Adjacent Regions}

Data from adjacent electrodes (Figure 5; Figure A1 for individual data) were also analyzed using the same timefrequency SPM analyses as for the third electrode in the lateral amygdala. The conjunction analyses were conducted to examine the areas in which more activity was observed for both faces versus mosaics and faces versus houses. The first electrode, which was located on the entorhinal cortex/ superficial amygdala, revealed only a nonsignificant trend toward greater activation in the gamma band at 200 $300 \mathrm{msec}$ (peak at $285 \mathrm{msec}, 70 \mathrm{~Hz}, Z=2.93$ ). The second 
electrode, which was located in the medial portion of the amygdala, revealed no significant activation. The fourth electrode, which was located on the border between the lateral amygdala and the white matter, revealed significantly more activity for faces than for control stimuli in the gamma band at 200-300 msec (peak at $285 \mathrm{msec}$, $68 \mathrm{~Hz}, Z=4.19$ ). The fifth electrode (medial border between the white matter and anterior temporal cortex) revealed no significant activation. The sixth electrode, which was located on the anterior temporal cortex, revealed a nonsignificant trend in the gamma band at $200-300 \mathrm{msec}$ (peak at $285 \mathrm{msec}, 68 \mathrm{~Hz}, Z=2.92$ ) toward more activity for faces than for control stimuli. No electrodes revealed other significant activity for the entire time-frequency range. In summary, with the exception of the fourth electrode located next to the lateral amygdala, adjacent electrodes showed activation patterns that differed from those of the lateral amygdala.

\section{DISCUSSION}

The results of time-frequency SPM analyses revealed that the lateral part of the amygdala showed greater gamma- band activation in response to faces than to mosaics and houses at 200-300 msec, with a peak at about $250 \mathrm{msec}$. Because participants were engaged in dummy tasks, amygdala activity can be regarded as primarily reflecting automatic processes in response to faces. Greater amygdala activation in response to faces compared with nonfacial stimuli is consistent with the results of previous neuroimaging studies (e.g., Blonder et al., 2004). However, the temporal dimension of such amygdala activation has remained unclear because of limitations associated with the temporal resolution of neuroimaging techniques. Amygdala activation in response to faces at 200-300 msec seems to corroborate previous single-unit recording data indicating that the mean latency of the amygdala face-related neurons was 240 msec (Kreiman et al., 2000). However, whether such neuronal responses actually corresponded to population level activity remained unclear. Because neurophysiological studies in animals have suggested that information is processed in the brain by populations of cells rather than by single cells (Pouget, Dayan, \& Zemel, 2000), data on population level activity are valuable for understanding the cognitive factors involved in processing faces. Although a previous intracranial ERP study (Halgren
Figure 5. Activation patterns of the lateral amygdala (third electrode) and adjacent regions. (A) A magnetic resonance image of a representative participant. A horizontal section is illustrated. (B) Grand-averaged time-frequency maps for faces, mosaics, and houses with baseline corrections. Results under both presentation conditions and for both hemispheres are combined. $\mathrm{F}=$ frequency; $\mathrm{T}=$ time. (C) Statistical parametric maps for conjunction analyses for faces versus mosaics and faces versus houses. $\mathrm{F}=$ frequency; $\mathrm{T}=$ time

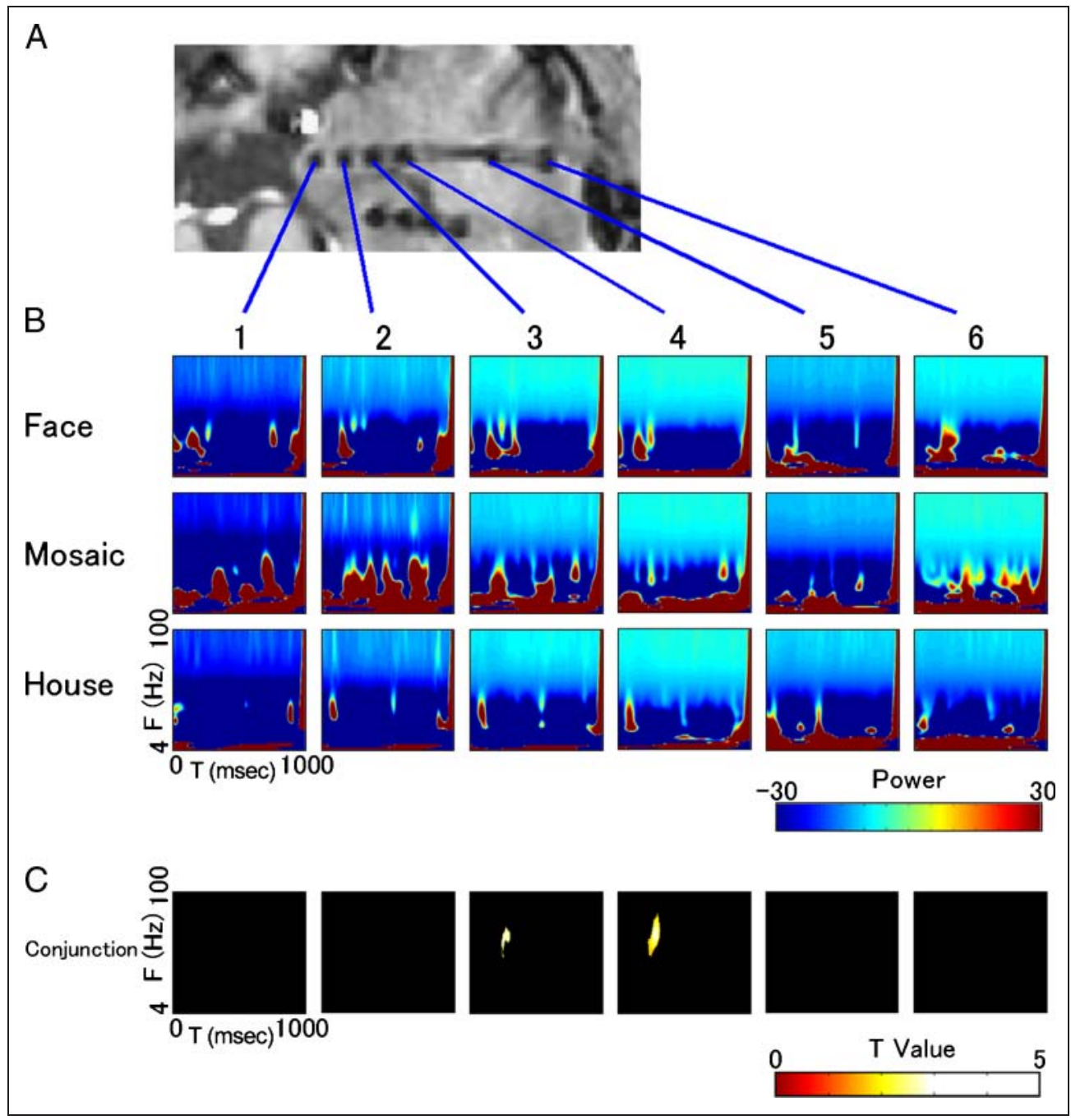


et al., 1994) and a scalp MEG study (Liu et al., 1999) did not show amygdala activity specific to faces compared with other stimuli, such null findings may be attributable to several methodological limitations [e.g., the frequency analyzed (Edwards et al., 2009) and the inverse problem (Mikuni et al., 1997)]. To our knowledge, this is the first reported study to demonstrate the temporal profile of the population level activity of neurons in the human amygdala during face processing.

So, what are the implications of amygdala activity at 200-300 msec for the understanding of face processing? First, some evidence has indicated that amygdala activity at 200-300 msec is not the earliest face processing in the brain. Several previous scalp (e.g., Bentin, Allison, Puce, Perez, \& McCarthy, 1996) and subdurally recorded ERP studies (e.g., Allison, Puce, Spencer, \& McCarthy, 1999) reported that the first face-specific brain activity occurred in the temporal cortex at approximately 150$200 \mathrm{msec}$ (for a review, see Rossion \& Jacques, 2008). This activity has been suggested to relate to face-specific visual encoding processes (Bentin et al., 1996). Anatomical studies in monkeys have shown that the amygdala receives projections from the visual areas in the temporal cortex (Amaral, Price, Pitkanen, \& Carmichael, 1992). On the basis of these data, we speculate that amygdala may receive the processed visual information from the temporal cortex and then conduct further processing for faces at 200-300 msec.

Second, several electrophysiological studies using scalp recordings have indicated that brain activity at about 200-300 msec was related to the conscious perception of visual stimuli (Koivisto et al., 2008; Koivisto, Revonsuo, \& Lehtonen, 2006; Wilenius-Emet, Revonsuo, \& Ojanen, 2004). Previous neuroimaging evidence has shown that cortical visual areas were involved in the conscious perception of faces (Andrews, Schluppeck, Homfray, Matthews, \& Blakemore, 2002; Tong, Nakayama, Vaughan, \& Kanwisher, 1998), and several studies have found functional connectivity between the amygdala and the same visual cortices used for processing facial stimuli (George, Driver, \& Dolan, 2001; Morris et al., 1998). Anatomical studies in monkeys showed that the amygdala sends widespread feedback projections to the visual areas (Amaral et al., 1992). Consistent with these neuroscientific data, behavioral studies have shown that the conscious perceptual processing of faces is highly efficient, including detection of (e.g., Lewis \& Edmonds, 2005) and attention toward (e.g., Bindemann et al., 2007) faces, compared with other objects. Taken together, these data suggest that the face-related activity of the human amygdala at 200-300 msec may be involved in the modulation of subjective perceptual processing in response to faces.

Our investigation of the inversion effect showed that the inverted presentation of faces had little effect on amygdala activity. This result is consistent with those of several previous neuroimaging studies that reported the absence of an effect by inverted/upright presentations of faces on amygdala activation (Joseph et al., 2006; Leube et al., 2003; however, see Epstein, Higgins, Parker, Aguirre, \& Cooperman, 2006). Our result appears to be inconsistent with some evidence from the behavioral literature, showing that the inverted presentation of faces impaired certain kinds of face processing, such as that required for the identification of individuals (for a review, see Valentine, 1988). However, consistent with the present results, some other behavioral experiments have reported that inverted presentations had little effect on other types of face processing, including detecting (Lewis \& Edmonds, 2005) and attending to (Bindemann \& Burton, 2008) faces. These data also suggest the possibility that face-specific amygdala gamma activity at 200-300 msec may be related to the subjective perception of faces.

We also found additional nonsignificant components in the amygdala activity in response to faces at 400-500 and 100-200 msec. In terms of face-related brain activity at 400-500 msec, several previous scalp-recorded ERP studies have suggested that the ERPs during about 400$600 \mathrm{msec}$ reflected accessing information about the face that was stored in semantic memory (e.g., Boehm \& Sommer, 2005; for a review, see Schweinberger \& Burton, 2003). Consistent with this, several previous neuroimaging (e.g., Bernstein, Beig, Siegenthaler, \& Grady, 2002) and neuropsychological (e.g., Broks et al., 1998) studies have suggested that the amygdala may be involved in the memory for faces. Given these data, it is possible that amygdala activity at $400-500 \mathrm{msec}$ may be related to the mnemonic processing of faces. With regard to amygdala activity at 100-200 msec, we measured amygdala field potentials while participants were viewing fearful, happy, and neutral facial expressions during a different assessment and found that higher gamma-band activity, peaking at $135 \mathrm{msec}$, was elicited in response to fearful versus neutral expressions (Sato et al., 2011). Some MEG studies have also reported that changes in amygdala activity were found at approximately $100 \mathrm{msec}$ while participants observed emotional versus neutral facial expressions (e.g., Maratos, Mogg, Bradley, Rippon, \& Senior, 2009; Luo, Holroyd, Jones, Hendler, \& Blair, 2007). In the context of these data, we speculate that amygdala activity at around $100 \mathrm{msec}$ may reflect the biological significance conveyed by faces. Our experimental procedures may have been insufficient to activate these psychological functions. Future studies should ask participants to explicitly process facial stimuli to thoroughly investigate the time-frequency profiles of amygdala activity related to face processing.

In addition to the time-frequency analyses, we also conducted ERP analyses. We found that the first clear components elicited by faces, mosaics, and houses were negative peaks at about $250 \mathrm{msec}$. Differences in peak amplitudes were not evident across stimulus types. These patterns are consistent with a previous intracranial ERP 
study that reported that first clear component was negative, peaking at 250-370 msec, and was elicited similarly in response to both faces and words (Halgren et al., 1994). The differing results between the ERP and timefrequency analyses may be attributable to their differential scopes in the frequency domain. Whereas ERP analysis can detect primarily low-frequency components (Edwards et al., 2009), time-frequency analysis allows detection of high- and low-frequency activity (Makeig et al., 2004). Some nonsignificant activities related to faces were observed in the ERP analyses. Future research using different tasks may more clearly reveal face-related ERPs in the amygdala.

We tested electrode sites other than those in the lateral amygdala and found that face-specific activity was not evident in the anterior temporal cortices. This result indicates that face-specific activity in the lateral amygdala does not reflect the spillover activation of adjacent temporal cortices. This result is consistent with previous reports indicating that intracranial field potential recordings may have a spatial resolution of a radius of about $1 \mathrm{~cm}$ (Lachaux et al., 2003; Menon et al., 1996). Our results also indicated that activation patterns in the amygdala may differ, which seems to imply the existence of intraamygdala functional segregation, a finding that has been previously reported in the animal literature (e.g., Swanson \& Petrovich, 1998). Given our sparse electrode placement and nonspecialized MRI protocol (cf. Solano-Castiella et al., 2010), future studies will be needed to further investigate the sub-regions of the amygdala.

Some methodological limitations of this study should be acknowledged. First, all participants were patients with epilepsy. Although visual inspection of the MRIs did not show clear anatomical abnormalities in these participants, a number of previous studies have reported microscopic anatomical abnormalities, such as neuronal cell loss and astrogliosis, in those with epilepsy (e.g., Aliashkevich et al., 2003; Yilmazer-Hanke et al., 2000). Thus, it is possible that such microscopic anatomical and/or functional abnormalities existed in the amygdalae of our participants. Thus, further investigations are necessary to confirm the present results in participants without epilepsy. However, the epileptic foci in the participants in the current study were not located in the amygdala, which was confirmed by electrophysiological and surgical evaluations. Interestingly, a previous study was unable to find neuronal loss or the presence of gliosis in the amygdalae of patients with epilepsy whose epileptic foci were located outside the amygdala (Zentner et al., 1999). The influence of possible microscopic abnormalities in the amygdala on the participants in this study is, thus, considered to be minimal.

Second, although we used standardized methods (Mihara \& Baba, 2001) employed in several previous studies (e.g., Usui et al., 2008), debate persists regarding the techniques involved in intracranial EEGs. For example, although we used the subdural electrodes embedded within the scalp as references, one technical study proposed that a wire electrode in subdermal scalp can be an easy and efficient reference (Vulliemoz, Spinelli, Pellise, Seeck, \& Ives, 2010). Several mathematical methods, such as current source density computations, can circumvent the reference electrode problem (Tenke \& Kayser, 2005). Application of these methodological improvements is an important challenge in future experiments.

In summary, our intracranial field potential recordings and time-frequency analysis in humans revealed that the amygdala showed greater gamma-band oscillations for faces than for mosaics or houses at 200-300 msec following stimulus onset. These results suggest that the human amygdala is involved in the early stages of face processing, such as the modulation of the subjective perception of faces. 


\section{APPENDIX}

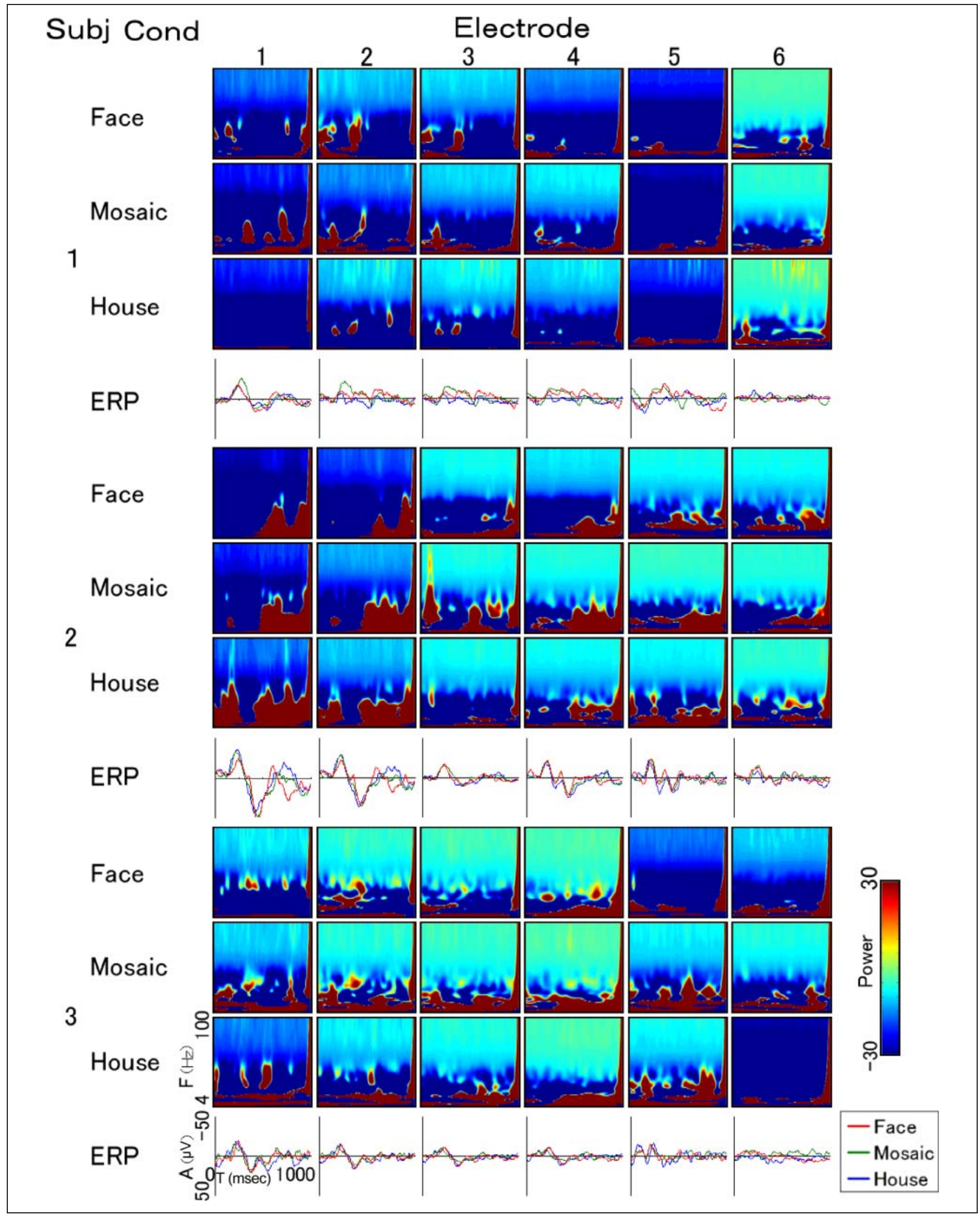

Figure A1. Time-frequency maps for faces, mosaics, and houses, and ERP waveforms for faces (red), mosaics (green), and houses (blue) with baseline corrections for each electrode of each participant. Results under both presentation conditions and for both hemispheres are combined. Subj = subject; Cond $=$ condition; $\mathrm{F}=$ frequency; $\mathrm{T}=$ time; $\mathrm{A}=$ amplitude. 


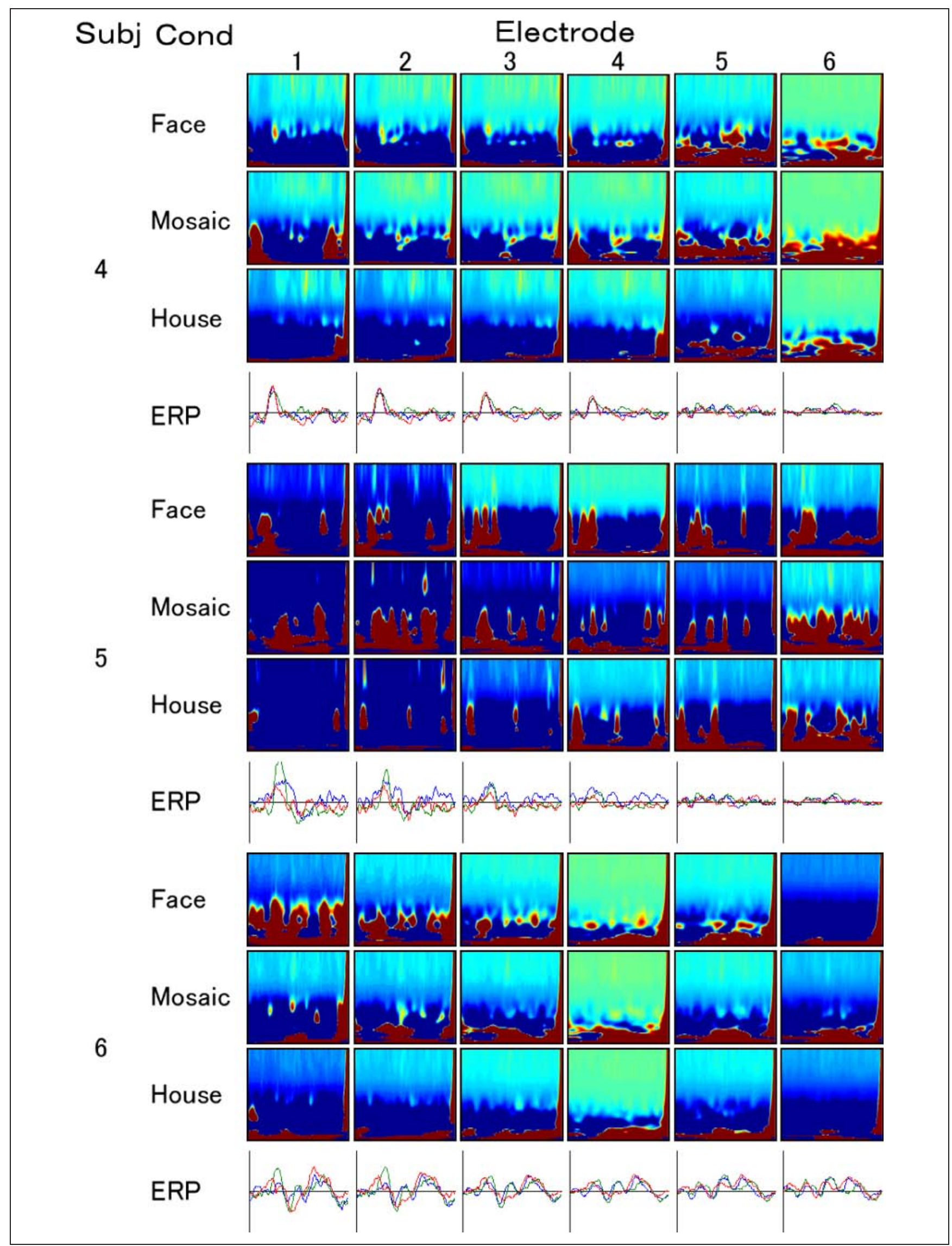

Figure A1. (continued). 


\section{Acknowledgments}

This study was supported by funds from the Benesse Corporation and JSPS Funding Program for Next Generation WorldLeading Researchers.

Reprint requests should be sent to Wataru Sato, The Hakubi Project, Primate Research Institute, Kyoto University, Inuyama, Aichi 484-8506, Japan, or via e-mail: sato@pri.kyoto-u.ac.jp.

\section{REFERENCES}

Aliashkevich, A. F., Yilmazer-Hanke, D., Van Roost, D., Mundhenk, B., Schramm, J., \& Blumcke, I. (2003). Cellular pathology of amygdala neurons in human temporal lobe epilepsy. Acta Neuropathologica, 106, 99-106.

Allison, T., Puce, A., Spencer, D. D., \& McCarthy, G. (1999) Electrophysiological studies of human face perception. I: Potentials generated in occipitotemporal cortex by face and non-face stimuli. Cerebral Cortex, 9, 415-430.

Amaral, D. G., Price, J. L., Pitkanen, A., \& Carmichael, S. T. (1992). Anatomical organization of the primate amygdaloid complex. In J. P. Aggleton (Ed.), The amygdala: Neurobiological aspects of emotion, memory, and mental dysfunction (pp. 1-66). New York: Wiley-Liss.

Andrews, T. J., Schluppeck, D., Homfray, D., Matthews, P., \& Blakemore, C. (2002). Activity in the fusiform gyrus predicts conscious perception of Rubin's vase-face illusion. Neuroimage, 17, 890-901.

Bentin, S., Allison, T., Puce, A., Perez, E., \& McCarthy, G. (1996). Electrophysiological studies of face perception in humans. Journal of Cognitive Neuroscience, 8, 551-565.

Bernstein, L. J., Beig, S., Siegenthaler, A. L., \& Grady, C. L. (2002). The effect of encoding strategy on the neural correlates of memory for faces. Neuropsychologia, 40, 86-98.

Bindemann, M., \& Burton, A. M. (2008). Attention to upside-down faces: An exception to the inversion effect. Vision Research, 48, 2555-2561.

Bindemann, M., Burton, A. M., Langton, S. R., Schweinberger, S. R., \& Doherty, M. J. (2007). The control of attention to faces. Journal of Vision, 7, 15.

Blonder, L. X., Smith, C. D., Davis, C. E., Kesler-West, M. L., Garrity, T. F., Avison, M. J., et al. (2004). Regional brain response to faces of humans and dogs. Brain Research, Cognitive Brain Research, 20, 384-394.

Boehm, S. G., \& Sommer, W. (2005). Neural correlates of intentional and incidental recognition of famous faces. Brain Research, Cognitive Brain Research, 23, 153-163.

Broks, P., Young, A. W., Maratos, E. J., Coffey, P. J., Calder, A. J., Isaac, C. L., et al. (1998). Face processing impairments after encephalitis: Amygdala damage and recognition of fear. Neuropsychologia, 36, 59-70.

Burrows, A. M. (2008). The facial expression musculature in primates and its evolutionary significance. Bioessays, 30, $212-225$.

Edwards, E., Soltani, M., Kim, W., Dalal, S. S., Nagarajan, S. S., Berger, M. S., et al. (2009). Comparison of time-frequency responses and the event-related potential to auditory speech stimuli in human cortex. Journal of Neurophysiology, 102, 377-386.

Epstein, R. A., Higgins, J. S., Parker, W., Aguirre, G. K., \& Cooperman, S. (2006). Cortical correlates of face and scene inversion: A comparison. Neuropsychologia, 44, 1145-1158.

Foucher, J. R., Otzenberger, H., \& Gounot, D. (2003). The BOLD response and the gamma oscillations respond differently than evoked potentials: An interleaved EEG-fMRI study. BMC Neuroscience, 4, 22.
Friston, K. J., Glaser, D. E., Henson, R. N., Kiebel, S., Phillips, C., \& Ashburner, J. (2002). Classical and Bayesian inference in neuroimaging: Applications. Neuroimage, 16, 484-512.

Friston, K. J., Holmes, A. P., \& Worsley, K. J. (1999). How many subjects constitute a study? Neuroimage, 10, 1-5.

Friston, K. J., Holmes, A. P., Price, C. J., Buchel, C., \& Worsley, K. J. (1999). Multisubject fMRI studies and conjunction analyses. Neuroimage, 10, 385-396.

George, N., Driver, J., \& Dolan, R. J. (2001). Seen gaze-direction modulates fusiform activity and its coupling with other brain areas during face processing. Neuroimage, 13, 1102-1112.

Halgren, E., Baudena, P., Heit, G., Clarke, J. M., \& Marinkovic, K. (1994). Spatio-temporal stages in face and word processing. I. Depth-recorded potentials in the human occipital, temporal and parietal lobes. Journal of Physiology, Paris, $88,1-50$.

Herrmann, C. S., Frund, I., \& Lenz, D. (2010). Human gamma-band activity: A review on cognitive and behavioral correlates and network models. Neuroscience and Biobehavioral Reviews, 34, 981-992.

Ishai, A., Schmidt, C. F., \& Boesiger, P. (2005). Face perception is mediated by a distributed cortical network. Brain Research Bulletin, 67, 87-93.

Johnson, M. H. (2005). Subcortical face processing. Nature Reviews Neuroscience, 6, 766-774.

Joseph, J. E., Gathers, A. D., Liu, X., Corbly, C. R., Whitaker, S. K., \& Bhatt, R. S. (2006). Neural developmental changes in processing inverted faces. Cognitive, Affective $\mathcal{E}$ Behavioral Neuroscience, 6, 223-235.

Karakas, S., Baar-Eroglu, C., Ozesmi, C., Kafadar, H., \& Erzengin, O. U. (2001). Gamma response of the brain: A multifunctional oscillation that represents bottom-up with top-down processing. International Journal of Psychophysiology, 39, 137-150.

Kilner, J. M., \& Friston, K. J. (2010). Topological inference for EEG and MEG. Annals of Applied Statistics, 4, 1272-1290.

Kilner, J. M., Kiebel, S. J., \& Friston, K. J. (2005). Applications of random field theory to electrophysiology. Neuroscience Letters, 374, 174-178.

Kilner, J. M., Mattout, J., Henson, R., \& Friston, K. J. (2005). Hemodynamic correlates of EEG: A heuristic. Neuroimage, 28, 280-286.

Koivisto, M., Lahteenmaki, M., Sorensen, T. A., Vangkilde, S., Overgaard, M., \& Revonsuo, A. (2008). The earliest electrophysiological correlate of visual awareness? Brain and Cognition, 66, 91-103.

Koivisto, M., Revonsuo, A., \& Lehtonen, M. (2006). Independence of visual awareness from the scope of attention: An electrophysiological study. Cerebral Cortex, $16,415-424$.

Kreiman, G., Koch, C., \& Fried, I. (2000). Category-specific visual responses of single neurons in the human medial temporal lobe. Nature Neuroscience, 3, 946-953.

Lachaux, J. P., Rudrauf, D., \& Kahane, P. (2003). Intracranial EEG and human brain mapping. Journal of Physiology, Paris, 97, 613-628.

LeDoux, J. E. (1996). The emotional brain: The mysterious underpinnings of emotional life. New York: Simon and Schuster.

LeDoux, J. E. (2000). Emotion circuits in the brain. Annual Review of Neuroscience, 23, 155-184.

Leube, D. T., Yoon, H. W., Rapp, A., Erb, M., Grodd, W., Bartels, M., et al. (2003). Brain regions sensitive to the face inversion effect: A functional magnetic resonance imaging study in humans. Neuroscience Letters, 342, $143-146$.

Lewis, M., \& Edmonds, A. (2005). Searching for faces in scrambled scenes. Visual Cognition, 12, 1309-1336. 
Litvak, V., Mattout, J., Kiebel, S. J., Phillips, C., Henson, R. N. A., Kilner, J., et al. (2011). EEG and MEG data analysis in SPM8. Computational Intelligence and Neuroscience, 852961.

Liu, L., Ioannides, A. A., \& Streit, M. (1999). Single trial analysis of neurophysiological correlates of the recognition of complex objects and facial expressions of emotion. Brain Topography, 11, 291-303.

Logothetis, N. K., Pauls, J., Augath, M., Trinath, T., \& Oeltermann, A. (2001). Neurophysiological investigation of the basis of the fMRI signal. Nature, 412, 150-157.

Luo, Q., Holroyd, T., Jones, M., Hendler, T., \& Blair, J. (2007). Neural dynamics for facial threat processing as revealed by gamma band synchronization using MEG. Neuroimage, 34, 839-847.

Makeig, S., Debener, S., Onton, J., \& Delorme, A. (2004). Mining event-related brain dynamics. Trends in Cognitive Sciences, 8, 204-210.

Maratos, F. A., Mogg, K., Bradley, B. P., Rippon, G., \& Senior, C. (2009). Coarse threat images reveal theta oscillations in the amygdala: A magnetoencephalography study. Cognitive, Affective, and Behavioral Neuroscience, 9, 133-143.

Menon, V., Freeman, W. J., Cutillo, B. A., Desmond, J. E., Ward, M. F., Bressler, S. L., et al. (1996). Spatio-temporal correlations in human gamma band electrocorticograms. Electroencephalography and Clinical Neurophysiology, 98, 89-102.

Mihara, T., \& Baba, K. (2001). Combined use of subdural and depth electrodes. In H. O. Luders \& Y. G. Comair (Eds.), Epilepsy surgery (2nd ed., pp. 613-621). Philadelphia, PA: Lippincott Williams \& Wilkins.

Mikuni, N., Nagamine, T., Ikeda, A., Terada, K., Taki, W., Kimura, J., et al. (1997). Simultaneous recording of epileptiform discharges by MEG and subdural electrodes in temporal lobe epilepsy. Neuroimage, 5, 298-306.

Morris, J. S., Friston, K. J., Buchel, C., Frith, C. D., Young, A. W., Calder, A. J., et al. (1998). A neuromodulatory role for the human amygdala in processing emotional facial expressions. Brain, 121, 47-57.

Nichols, T., Brett, M., Andersson, J., Wager, T., \& Poline, J.-B. (2005). Valid conjunction inference with the minimum statistic. Neuroimage, 25, 653-660.

Niessing, J., Ebisch, B., Schmidt, K. E., Niessing, M., Singer, W., \& Galuske, R. A. (2005). Hemodynamic signals correlate tightly with synchronized gamma oscillations. Science, 309, 948-951.

Oldfield, R. C. (1971). The assessment and analysis of handedness: The Edinburgh inventory. Neuropsychologia, 9, 97-113.

Oya, H., Kawasaki, H., Howard, M. A., III, \& Adolphs, R. (2002). Electrophysiological responses in the human amygdala discriminate emotion categories of complex visual stimuli. Journal of Neuroscience, 22, 9502-9512.

Papadelis, C., Poghosyan, V., Fenwick, P. B., \& Ioannides, A. A. (2009). MEG's ability to localise accurately weak transient neural sources. Clinical Neurophysiology, 120, 1958-1970.

Pouget, A., Dayan, P., \& Zemel, R. (2000). Information processing with population codes. Nature Reviews Neuroscience, 1, 125-132.

Purcell, D. G., \& Stewart, A. L. (1988). The face-detection effect: Configuration enhances detection. Perception and Psychophysics, 43, 355-366.

Reinders, A. A., den Boer, J. A., \& Buchel, C. (2005). The robustness of perception. European Journal of Neuroscience, 22, 524-530.

Rossion, B., \& Jacques, C. (2008). Does physical interstimulus variance account for early electrophysiological face sensitive responses in the human brain? Ten lessons on the N170. Neuroimage, 39, 1959-1979.

Sato, W., Kochiyama, T., Uono, S., Matsuda, K., Usui, K. Inoue, Y., et al. (2011). Rapid amygdala gamma oscillations in response to fearful facial expressions. Neuropsychologia, 49, 612-617.

Schweinberger, S. R., \& Burton, A. M. (2003). Covert recognition and the neural system for face processing. Cortex, 39, 9-30.

Solano-Castiella, E., Anwander, A., Lohmann, G., Weiss, M., Docherty, C., Geyer, S., et al. (2010). Diffusion tensor imaging segments the human amygdala in vivo. Neuroimage, 49, 2958-2965.

Swanson, L. W., \& Petrovich, G. D. (1998). What is the amygdala? Trends in Neurosciences, 21, 323-331.

Tanaka, J. W., \& Farah, M. J. (1993). Parts and wholes in face recognition. Quarterly Journal of Experimental Psychology, Section A, Human Experimental Psychology, 46, 225-245.

Tenke, C. E., \& Kayser, J. (2005). Reference-free quantification of EEG spectra: Combining current source density (CSD) and frequency principal components analysis (fPCA). Clinical Neurophysiology, 116, 2826-2846.

Theeuwes, J., \& Van der Stigchel, S. (2006). Faces capture attention: Evidence from inhibition of return. Visual Cognition, 13, 657-665.

Tong, F., Nakayama, K., Vaughan, J. T., \& Kanwisher, N. (1998). Binocular rivalry and visual awareness in human extrastriate cortex. Neuron, 21, 753-759.

Tottenham, N., Leon, A. C., \& Casey, B. J. (2006). The face behind the mask: A developmental study. Developmental Science, 9, 288-294.

Usui, N., Terada, K., Baba, K., Matsuda, K., Tottori, T., Umeoka, S., et al. (2008). Extraoperative functional mapping of motor areas in epileptic patients by high-frequency cortical stimulation. Journal of Neurosurgery, 109, 605-614.

Valentine, T. (1988). Upside-down faces: A review of the effect of inversion upon face recognition. British Journal of Psychology, 79, 471-491.

Vulliemoz, S., Spinelli, L., Pellise, D., Seeck, M., \& Ives, J. R. (2010). A new ground and reference technique for invasive EEG recordings. American Journal of Electroneurodiagnostic Technology, 50, 50-58.

Wilenius-Emet, M., Revonsuo, A., \& Ojanen, V. (2004). An electrophysiological correlate of human visual awareness. Neuroscience Letters, 354, 38-41.

Woldorff, M. G. (1993). Distortion of ERP averages due to overlap from temporally adjacent ERPs: Analysis and correction. Psychophysiology, 30, 98-119.

Worsley, K. J., Marrett, S., Neelin, P., Vandal, A. C., Friston, K. J., \& Evans, A. C. (1996). A unified statistical approach for determining significant signals in images of cerebral activation. Human Brain Mapping, 4, 58-73.

Yilmazer-Hanke, D. M., Wolf, H. K., Schramm, J., Elger, C. E., Wiestler, O. D., \& Blumcke, I. (2000). Subregional pathology of the amygdala complex and entorhinal region in surgical specimens from patients with pharmacoresistant temporal lobe epilepsy. Journal of Neuropathology and Experimental Neurology, 59, 907-920.

Yin, R. K. (1969). Looking at upside-down faces. Journal of Experimental Psychology, 81, 141-145.

Zentner, J., Wolf, H. K., Helmstaedter, C., Grunwald, T., Aliashkevich, A. F., Wiestler, O. D., et al. (1999). Clinical relevance of amygdala sclerosis in temporal lobe epilepsy. Journal of Neurosurgery, 91, 59-67. 